Running head: Secondary school renewal and classroom culture

Title: Secondary school renewal: the effect of classroom learning culture on educational outcomes

Authors: Robert F. Cavanagh,

Curtin University of Technology

Perth, Western Australia

Russell F. Waugh

Edith Cowan University

Perth, Western Australia

Address correspondence to: Dr Rob Cavanagh,

Department of Education,

Curtin University of Technology

GPO Box U1987

Western Australia 6845

Email: $\quad$ R.Cavanagh@curtin.edu.au

Phone: $\quad$ +61892662162

Fax: $\quad$ +6189266 2547 


\begin{abstract}
The study was grounded on theoretical propositions and empirical research concerning school effectiveness, classroom effectiveness, school improvement and school renewal. In particular, the notion that improving student learning outcomes through improving and renewing schools is dependent on changing classroom cultures of learning and teaching.
\end{abstract}

A model of classroom culture consisting of student educational values (dependent variable), formal learning outcomes (dependent variable), and the attitudes and behaviours of students, the teacher and parents (independent variables) was proposed. Hypothesised relationships between the dependent and independent variables were tested by multiple regression analysis of data from 988 students obtained from administration of a Rasch model classroom culture instrument. The classroom learning attitudes and behaviours of students were found to directly relate to educational outcomes, as were teacher expectations and parent attitudes and behaviours. The attitudes and behaviours of students and teachers towards classroom collaboration and caring were not confirmed to directly relate to learning outcomes.

The findings of the investigation are discussed in consideration of the theoretical assumptions upon which the study was based. This discussion includes identification of the implications of the empirical results for understanding and facilitating renewal of secondary schools with the intention of improving educational outcomes in classrooms.

Keywords: classroom culture, educational change, educational outcomes, learning environments, school culture, school improvement, school renewal, secondary schools 


\section{SECONDARY SCHOOL RENEWAL: THE EFFECT OF CLASSROOM LEARNING CULTURE ON IMPROVING EDUCATIONAL OUTCOMES}

The impetus for school effectiveness research originally came from assertions and evidence that educational achievement was a consequence of factors external to the school. In response, school effectiveness research focused on ascertaining whether or not differences in resourcing, processes and organisational arrangements in schools affected student outcomes. Research findings were applied in the design of school improvement programs which typically intended to change learning conditions and other related internal conditions to enable more effective accomplishment of educational goals. The results of school effectiveness research suggest that sustainable school improvement requires changing school and classroom culture; changing beliefs, values, attitudes and behaviours concerning the learning of students.

Studies of the reform of education since the early 1990's have been critical of school improvement initiatives based upon organisational restructuring and top-down change processes that fail to recognise the “... depth range and complexity of what teachers do" (Bascia \& Hargreaves, 2000 p. 4). Alternatively, school improvement and the more recent notion school renewal, have been portrayed as a process of re-culturing to change belief and value systems throughout the school (Dalin, Rolff \& Kleekamp, 1993; Fullan, 1993;

Glickman, 1992; Harris, 2001). Sirotnik (1999, p.608) proposed that renewal was characterised by teacher responsibility concerning a moral obligation to "create and nurture learning environments for their students as well as themselves”. 
The development of collaborative and collegiate school cultures with schools having multiple leaders have been proposed as vital to school improvement and effectiveness (Crowther, Kaagan, Fergusson \& Hann, 2002; Fullan \& Hargreaves, 1992). However collaboration and collegiality are typically viewed from the perspective of relationships between staff. Since beliefs and values about student learning are the central component of school culture, re-culturing needs to extend into the classroom to change and renew classroom cultures of teaching and learning. (Hargreaves, 1995; Glickman, 1992). Transforming the culture of a school requires teachers to develop new beliefs, attitudes and values about instructional processes that will lead to change in classroom practice and improved student educational outcomes (Halsall, 1998). Although classroom pedagogy and student achievement are at the core of the school improvement, implementation of school improvement programs does not necessarily lead to improved student learning (Lingard, 2001; Newmann \& Associates, 1996; Queensland Department of Education, 2001). It cannot be assumed that reforming the organisation of the school, the curriculum or the learning environment will positively impact on student learning. There is a need to test this view in Western Australian schools.

Boland, Cavanagh and Dellar (2001) conducted a longitudinal study of a secondary school undergoing renewal. Data collected from teachers, students and parents evidenced changes in the physical conditions within the school, the structure of the school organisation, the curriculum, and in classroom learning environments, but not in educational outcomes. Conditions anticipated to be conducive to improved learning were created but improved learning did not occur. This finding was explained in terms of lack of change in classroom culture, and lack of change in teacher and student beliefs, values and behaviours towards learning. The failure of the reform and re-culturing process is probably due to the locus of control of the change process not being at the classroom level. Advocates of school renewal 
emphasise the need for a bottom-up change process in which teachers challenge prevailing beliefs and practices within the school (Sirotnik, 1999; Soder, 1999). The renewal of schools requires re-culturing the individual classroom by the development of alternative beliefs and attitudes towards classroom instruction and learning. Attention should also be given to the processes by which these pedagogical beliefs and attitudes can be changed.

The development and maintenance of classroom culture can be viewed as a process of social constructivist learning. Social constructivism emphasises the importance of the social environment on the acquisition and development of knowledge (Blumenfield, Marx, Patrick, Krajcik, \& Soloway, 1997; Good \& Brophy, 2000). Adoption of a social constructivist view of classroom culture and student learning supports the instructional importance of the social processes occurring within the classroom for learning. This is consistent with cooperative learning instructional methods (Johnson, Johnson \& Stanne, 2000), and also propositions about the effectiveness of caring learning environments (Battistitch, Solomon, Watson \& Schaps, 1997; Pena \& Amrein, 1999). In addition, the dispositions and behaviours of students within the classroom are also influenced by home and family, the effect of family and home on student achievement is well established (Coleman, 1998; Lingard, 2001; Waugh \& Cavanagh, 2002a \& 2002b). So accepting the social constructivist view of learning involves investigating classroom learning and teaching in relation to the factors influencing students' mental construction of the socio-psychological environment constituting classroom culture.

The context for the study was pressure from the government and state educational system for school reform through curriculum reform. The Western Australian Curriculum Framework (Curriculum Council, 1997) is based upon the notion of outcomes based education. It is characterised by identification of sequential long-term educational goals in comparison to previous curricula that prescribed the objectives of specific courses of study, 5 
units of work or years of schooling. Five Core Values underpin the Curriculum Framework: pursuit of knowledge and achievement of potential; self-acceptance and self-respect; respect and concern for the rights of others; social and civic responsibility; and environmental responsibility. The Curriculum Framework also specifies seven Key Principles to guide schools in planning and curriculum development: an encompassing view of the curriculum; an explicit knowledge of the core values; flexibility; inclusivity; integration, breadth and balance; a developmental approach; and collaboration and partnerships. Although the theoretical grounding of this study was findings from many years of international research into effective classrooms and schools, the researchers were well aware of the local context and of the need for conducting research to inform improvement of conditions in Western Australian classrooms.

\section{THEORETICAL MODEL}

The conception of classroom culture applied in the study assumed that it could be viewed as a system involving multiple influences; the values and behaviours of the class group, of the teacher, and of parents. An effective classroom culture was postulated to be characterised by student attainment of educational outcomes. Educational outcome attainment affects student satisfaction with prior learning experiences and provides motivation for further learning. Educational outcomes can be viewed as both an element of classroom culture (Cavanagh \& Dellar, 2001) and as the result of an effective classroom culture.

Educational outcome attainment is typically evidenced by student performance in teacher assessment of specific aspects of learning. For example, in local secondary schools, the instructional program implemented by teachers is usually only one component (subject or 
learning area) of the overall school curriculum and is typically delivered and formally assessed within a period of 20 weeks or less. In the model of classroom culture guiding the study (see Figure 1), the outcomes of short-term subject-specific classroom instruction were designated formal learning outcomes. However, educational outcome attainment is also evidenced by the long-term development of positive attitudes towards education, students placing high importance on their schooling and being confident that achievement of their goals can be realised through continual learning. In the model, this educational outcome was designated student educational values.

Place Figure 1 about here

Classroom culture results from attitudes towards learning, social interaction and consequent classroom behaviours. Classroom attitudes and behaviours are the central component of the model. Group attitudes and behaviours towards learning concern the emphasis placed on learning by students, students learning from each other and expecting they will all perform well. Group attitudes and behaviours towards interaction with peers was included in the model on assumption that learning would be enhanced by a classroom social environment in which students support and care for peers and in which there is discussion about classroom activity and the instructional program. Teacher attitudes and behaviour towards students and instruction was included in recognition of the teacher's role in establishing and maintaining a classroom culture through shared decision-making with students, caring for students and having high expectations of all students. Parent Attitudes and behaviours towards child and teacher were also assumed to be part of classroom culture, 
parents collaborating with the teacher by taking an interest in their child's schooling and monitoring academic progress.

Model development assumes that valuing education and schooling would influence, and be influenced, by the other elements of classroom culture including class group, teacher and parent attitudes and behaviours. Student educational values and formal learning outcomes were also anticipated to influence and be influenced by these elements. These relationships are represented by the double arrows in Figure 1.

\section{RESEARCH OBJECTIVES}

The study sought to test two hypotheses concerning relationships between educational outcomes and elements of classroom culture.

1. What is the relationship between student educational values (as the dependent variable) and four groups of independent variables? These were group attitudes and behaviours towards learning, group attitudes and behaviours towards interaction with peers, teacher attitudes and behaviours towards students and instruction, and parent attitudes and behaviours towards child and teacher.

2. What is the relationship between student formal learning outcomes (as dependent variable) and the four groups of independent variables? 


\section{METHOD}

The research approach was an example of what Fraenkel and Wallen (2001) described as correlational research. This method seeks to describe a phenomenon by examining relationships between variables without manipulation of any of the variables. The components of the theoretical model (Figure 1) were treated as either dependent or independent variables. A survey-type instrument was administered to provide continuous numerical data on all 14 variables. Multiple regression was applied to test hypothesised relationships between the dependent and independent variables.

$\underline{\text { Instrumentation }}$

Data were collected by administration of the Classroom Environment and Educational Outcomes Questionnaire (Waugh \& Cavanagh, 2002a). This uni-dimensional, ordinal and interval scale (see Appendix) was developed by application of the Rasch model (Wright \& Masters, 1982) through use of the computer program RUMM (Andrich, Sheridan, Lyne \& Luo, 2000). Analysis of data obtained from a sample of 521 students in three Western Australian secondary schools was used to develop the original instrument (Waugh \& Cavanagh, 2002a). As applied in the study, the questionnaire was considered to comprise two dependent variables and 12 independent variables (see Table 1) - independent variables were organised according to the four elements of classroom culture in the theoretical model. Items were answered on a four point Likert scale from strongly agree, agree, disagree and strongly disagree, scored from 4 to 1.

Place Table 1 about here 
$\underline{\text { Sample }}$

Students $(\mathrm{n}=988)$, from 53 classes in a large Western Australian comprehensive secondary school completed the survey. Table 2 presents school population details and the respective numbers of valid surveys returned for data entry. Year Twelve students were not surveyed due to public examination commitments (the Tertiary Entrance Examination). Although the school staff had collectively given an undertaking to participate in the study, some individual teachers failed to administer the survey in their classes and, in the classes surveyed, some students did not complete the survey. This meant that the sample, although large, was smaller than expected.

Stratified sampling was applied to obtain a sample representative of the major subject areas and year cohorts. Table 3 presents the distribution of classes within each year cohort and the subject areas.

Place Tables 2 and 3 about here

Data Analysis

Cronbach's Alpha was calculated to test the internal reliability of the respective instrument scales measuring each of the 14 variables. Likert scale responses to the items comprising each of these scales were then aggregated to provide numerical scores for the 14 10 
variables. Aggregated data were initially analysed by examining the zero-order correlations between all variables. Two multiple regressions with student educational values and formal learning outcomes being treated as the respective dependent variables were then conducted. The other twelve variables measured by the instrument were treated as independent variables. Hypothesised relationships between the two educational outcome variables and the twelve other classroom culture variables were then examined by multiple regression. The twelve independent variables were step-wise regressed against the dependent variables.

Confirmation of a relationship required a level of probability less than 0.01 that the relationship was due to random fluctuations in the data. The nature of the relationship (direct or inverse) was indicated by the respective positive or negative value of the slope coefficient (B) and the effect of variation in the independent variables upon variation in dependent variables (strength of association) was calculated for each relationship. Beta weight $(\beta)$ was calculated to provide a standardised measure of the strength of association between each of the 12 independent variables and each of the two independent variables $(\beta>0.15)$. The cumulative effect of variation in the independent variables on each of the two independent variables was measured by calculating R Square.

\section{RESULTS}

Calculation of Cronbach’s Alpha for the data of instrument scales revealed that overall internal reliability was high (see Table 4). Also, the internal reliability of the data for the dependent variable scales were high as were the reliability of the data for measuring the four groups of independent variables Although there were varying internal reliability within the 
twelve independent variable scales, with the exception of class learning with peers ( $\alpha=$ 0.49), the data were internally reliable.

Place Table 4 about here

The first result to note from the correlational analyses is the presence of positive correlations between all 14 variables (see Tables 5 \& 6). There were varying levels of correlation between the respective variables within each group of independent variables (see table 5). Correlations were strongest within group attitudes and behaviours towards learning and group attitudes and behaviours towards interaction with peers. However, the variables comprising teacher attitudes and behaviour towards students and instruction were less strongly correlated mainly due to the teacher's expectations for students variable. Correlation between variables within the three groups is reflected in the overall range of correlations between the 12 variables indicating that the 12 independent variables were related to varying degrees. This finding is conceptually consistent with the systems representation of classroom culture which assumed the elements of classroom culture would be inter-dependent. Interdependency between variables is further evidenced by the varying levels of positive correlation between the 12 independent variables the two dependent variables; student educational values and formal learning outcomes (see Table 5). Although evidence exists of association between pairs of variables, there is a need to test assumptions between the dependent variables and independent variables as a group because this may show different effects. 
Place Tables 5 and 6 about here

Regression analysis was used to test for a group relationship between the first dependent variable (student educational values) and the 12 independent variables. Multiple regression was applied in cognisance of covariance in independent variable data, as evidenced by the separate pair-wise correlations between the variables (multi-co-linearity). The 12 independent variables were stepwise regressed against the dependent variable. The independent variables accounted for $41 \%$ (R Square 0.41 ) of the variance in student educational values (dependent variable) (see Table 7). The dependent variable, student educational values was confirmed to have strong positive relationships with class emphasis on learning $(\mathrm{B}=0.89, \mathrm{p}<0.01)$, class learning with peers $(\mathrm{B}=0.45, \mathrm{p}<0.01)$, class emphasis on performing well $(\mathrm{B}=0.40, \mathrm{p}<$ 0.01), teacher's expectations for students $(\mathrm{B}=0.89, \mathrm{p}<0.01)$ and parent attitudes and behaviours $(\mathrm{B}=2.78, \mathrm{p}<0.01)$. This dependent variable had a confirmed inverse relationship with teacher's behaviour to caring $(\mathrm{B}=-0.22, \mathrm{p}<0.01)$. Only four of the variables had significant Beta weights, indicating that when the independent variables had a unit change, the dependent variable had the Beta weight change. These were in order, $\beta=$ 0.33 for class emphasis on learning, $\beta=0.18$ for class emphasis on performing well, $\beta=0.13$ for teacher's expectations for students, and $\beta=-0.11$ for teacher's behaviour to caring. This last Beta weight shows an unexpected inverse relationship. That is, students believe that when there is a unit positive change in teacher's caring behaviour, student educational values decrease. This might be explained if caring is associated with being a weak teacher, leading to low learning. 
Place Table 7 about here

The 12 independent variables accounted for 39\% (R Square 0.39 ) of the variance in the dependent variable formal learning outcomes (see Table 8). Formal learning outcomes was confirmed to have strong positive relationships with class emphasis on learning $(\mathrm{B}=0.36$, $\mathrm{p}$ $<0.01)$, class emphasis on performing well $(\mathrm{B}=0.49, \mathrm{p}<0.01)$, getting along together $(\mathrm{B}=$ 0.36, $\mathrm{p}<0.01)$, teacher's expectations for students $(\mathrm{B}=0.51, \mathrm{p}<0.01)$, and parent attitudes and behaviours $(\mathrm{B}=0.25, \mathrm{p}<0.01)$. This dependent variable had a confirmed inverse relationship with caring about each other $(\mathrm{B}=-0.28, \mathrm{p}<0.01)$. The six variables had significant Beta weights. These were, in order, $\beta=0.22$ for class emphasis on performing well, $\beta=0.18$ for teacher's expectations for students, $\beta=0.15$ for class emphasis on learning, $\beta=0.15$ for getting along together, $\beta=0.15$ for parent attitudes and behaviours, and $\beta=$ 0.11 for caring about each other. This last Beta weight shows an unexpected inverse relationship. That is students believe that when there is a unit positive change in students caring about each other, then formal learning outcomes decrease by 0.11 . 
Place Table 8 about here

The results show strong associations between the two educational outcome variables and approximately one third of the classroom culture variables measured by the instrument. This finding provides partial confirmation of the two hypotheses concerning relationships between educational outcomes and the elements of classroom culture investigated.

\section{DISCUSSION}

Social constructivist pedagogy is a feature of the local curriculum, the Curriculum Framework. The Curriculum Framework is prefaced by attitudinal statements about participation in society and a developmental approach towards student learning. The Curriculum Framework was also designed in the expectation that the outcomes of learning can be specified and that appropriate learning environments would facilitate attainment of these outcomes. It is the lynchpin of local educational reform and school renewal, and its implementation has provided an ideal context for investigating how classroom culture could be related to improving the educational outcomes of students.

The following section of this report commences with an examination of the statistical correlations between the elements of classroom culture in relation to the construct validity of the theoretical model of classroom culture applied in the study. This is followed by discussion of the results of the multiple regressions that were conducted to test hypothesised 
relationships between the 12 classroom attitude and behaviour variables (independent variables) and the two educational outcome variables (dependent variables). Finally, the findings of the study are considered in relation to various aspects of school renewal.

\section{Construct Validity of the Theoretical Model of Classroom Culture}

The central component of the theoretical model was constituted by four groups of classroom culture elements; group attitudes and behaviours towards learning, group attitudes and behaviours towards interaction with peers, teacher attitudes and behaviour towards students and instruction and parent attitudes and behaviours towards child and teacher. There were positive correlations between the 12 variables comprising these groups of attitudes and behaviours. This finding supports the original assumption of the model that the attitudes and behaviours of the classroom group are inter-related with those of the teacher and the parent. Students, the teacher and parents are mutually influential and collectively influence the classroom culture. This supports the recent work of Coleman (1998). There were moderate to high positive correlations between the respective elements comprising the learning and peer interaction components of the model. The group attitudes and behaviours of the students towards learning were characterised by class emphasis on learning, class learning with peers and class emphasis on performing well. Students helping each other, getting along together, caring about each other and engaging in classroom discussion characterised group attitudes and behaviours towards learning. There was less consistency in the correlations between the elements of teacher attitudes and behaviours towards students and instruction. Student classroom planning behaviour, teacher's behaviour towards decision-making and teacher's behaviour towards caring were correlated but not related to teacher's expectations for students. 
There appears to be a dichotomy in how the teacher influences classroom culture. On one hand there were collaborative and caring behaviours towards students and, on the other, the teacher expressing expectations about how the students should behave. The behavioural expectations of the teacher (as seen by the students) were independent of the teacher's proclivity for collaborating with students and being caring of students. Some teachers exhibited both types of behaviour, others exhibited a combination or one or other of these behaviours, and others did not exhibit either behaviour. This inconsistency between elements within the teacher attitudes and behaviour towards students and instruction component of the theoretical model provides justification for modifying the model by replacing this group with two discrete groups. These could be teacher attitudes and behaviours towards collaboration and caring and teacher attitudes and behaviour towards classroom control.

The theoretical model assumed the four groups of classroom culture elements would influence, and be influenced by, student educational outcomes. The range and direction of the respective correlations between the independent variables and the two dependent variables is consistent with this assumption. This finding supports the view of classroom culture being a system comprised of the outcomes of learning within the classroom in conjunction with the previously identified attitudes and behaviours of students, the teacher and parents. Group attitudes and behaviours towards learning were most strongly correlated with educational outcomes. A classroom culture in which students recognise the importance of learning, discuss their learning with peers and are motivated to towards high academic performance is anticipated to develop positive values towards education and the attainment of formal learning outcomes.

Confirmed Relationships between Classroom Attitudes and Behaviours and Educational

\section{$\underline{\text { Outcomes }}$}


The results of regressing the independent variables against the dependent variables are generally consistent with those obtained from correlating these variables. However there were some inconsistencies in the results from these two analyses. For example, regressing the independent variable teacher's behaviour to caring against the dependent variable student educational values confirmed an inverse relationship $(B=-0.22, \beta=-0.11 \& p<0.01)$, whereas analysis of correlation between the variables revealed a low positive correlation $(r=$ .12). The inconsistency is due to the particular types of correlation and regression analyses that were applied. Zero order correlations were calculated which do not control for the effect of other variables on the correlation between the two variables being examined. Alternatively in the regression analyses, relationships between variables were identified by application of multiple regression in which the covariance between independent variables affects determination of the relationships between particular dependent independent variables. In multiple regression, the Beta weight $(\beta)$ is particularly important since it provides a measure of the strength of association between the variables by comparing the variance in two variables independently of other variables that are held constant.

The first multiple regression involved the dependent variable student educational values. Valuing education, schooling and learning by students may well be the pre-cursor for their engagement in further education and life-long learning. The development of these values is a high-order educational outcome transcending acquirement of the knowledge and skills required to master prescribed learning outcomes in specific areas of the curriculum. The confirmation of a relationship ( $\beta=0.33)$, between student educational values and class emphasis on learning for the sample of students surveyed from different year levels and across different subject areas is significant. Classroom cultures that emphasise improving the 
learning of students facilitate the development of positive student values towards education and schooling. Development of these values is also enhanced by students expecting that they can be academically successful. Class emphasis on performing well had a confirmed positive relationship with student educational values $(\beta=0.18)$. Student perceptions of being academically successful in the classroom were related to the importance they placed on their education and schooling. Development of this orientation towards education is also enhanced by the teacher expressing the need for high academic and behavioural expectations within the classroom Student educational values were also found to be positively related to teacher's expectations for students $(\beta=0.13)$.

The confirmed inverse relationship between student perceptions of teacher's behaviour to caring and student educational values $(\beta=-0.11)$ is particularly significant since it is contradictory to current research into teacher caring (Battistitch, Solomon, Watson \& Schaps, 1997; Pena \& Amrein, 1999). This finding may be due to differing levels of sensitivity towards the need for personal support from the teacher between students who place high value on their education and those who do not. Students who have a need for assistance in resolving problems arising at home or at school, may have a heightened awareness of teacher caring. The lack of direct association between this teacher behaviour and the presence of positive values towards education and schooling could result from the influence of individualised relationships between the teacher and certain students that are independent of the collective attitudes and behaviours comprising classroom culture. There could be another dimension of the classroom psycho-social environment constituted of individual attitudes and behaviours that have not become group attitudes and behaviours through the social interaction that produces the culture. Aspects of this dimension could become part of the culture if they are sufficiently prevalent to be characteristic of the group and not just of a 
small number of individuals. This probably did not occur with teacher's behaviour to caring in the sample of secondary school classrooms investigated.

The second multiple regression involved the dependent variable formal learning outcomes. Formal learning outcomes are the short to medium term objectives of the instructional program pertinent to specific subjects or learning areas of the curriculum. These outcomes are made explicit to students by the teacher and are usually formally assessed with assessment results being aggregated and reported to parents. Attainment of formal learning outcomes is typically evaluated by tests and assignments which are marked by the teacher and graded. The grading process applies pre-determined assessment criteria based upon both curriculum objectives and assumptions about the hierarchical order of these objectives. The ordering of objectives is specified in the curriculum as a linear sequence of stages of learning or developmental learning continuum. This enables recording of assessment results as grades or numbers and provides quantitative data that is useful in evaluating teacher performance, the success of instructional programs and overall school performance. These data are frequently reported to school councils and the educational system, and they are also used for school improvement planning. These applications of assessing formal learning outcomes provide data for accountability and organisational development purposes.

An alternative application of these data is in evaluating the effectiveness of the teaching and learning in individual classrooms. In this instance, the data are used for diagnostic purposes to identify associations between the outcomes and particular attributes of the classroom learning environment to inform improvement of instruction and learning. Attainment of formal learning outcomes was associated with class emphasis on learning ( $\beta=$ $0.15)$ and class emphasis on performing well $(\beta=0.22)$. These associations could be 
interpreted by assuming that learning outcomes and classroom attitudes and behaviours towards learning are identical constructs. However, the learning outcomes construct concerns student perceptions of their performance on tasks nominated by the teacher or prescribed in the curriculum. Alternatively, the attitudes and behaviours towards learning construct centres on the expectation that learning is possible and having confidence that particular behaviours will facilitate learning. A classroom culture in which students themselves continually emphasise the importance of the instructional program and academic performance is conducive to improved learning outcomes.

This culture and resulting academic performance are further enhanced by the presence of harmonious relationships between students. Getting along together was associated with formal learning outcomes $(\beta=0.15)$. The expectations of the teacher about student behaviour are likewise important for developing and maintaining a classroom culture that enables student learning. Teacher's expectations for students are associated with formal learning outcomes ( $\beta=0.18$ ). This culture is influenced by the teacher setting high standards for all aspects of classroom activity, particularly student commitment to their work. These requirements are communicated to students and understood by students. In addition to classroom culture and learning outcomes being influenced by the student group and the teacher, the attitudes and behaviours of parents are also influential. Parent attitudes and behaviours were associated with formal learning outcomes $(\beta=0.15)$. The children of parents who take an interest in the academic progress of their child, engage in communication with the teacher and express confidence in the teacher's professional ability, are more likely to be academically successful. 
The confirmed inverse relationship between student perceptions of caring about each other and formal learning outcomes $(\beta=-0.11)$ was not anticipated. A classroom culture in which students are amiable, tolerant and caring of classmates was expected to support academic achievement. To the contrary, students who perceived higher levels of caring between peers also reported low attainment of formal learning outcomes. Developing respect and concern for the rights of others is an important component of local, national and international curriculum policies (Curriculum Council, 1997; MCEETYA, 2000; Stoll, MacBeath \& Mortimore, 2001). When viewed from this perspective, peer caring in the classroom could be considered as an educational outcome rather than as an element of classroom culture. If this proposition is accepted, it is likely that developing caring between students within the classroom and academic performance are independent, and there may be a tension between the respective instructional strategies and classroom conditions necessary for attainment of these two independent outcomes.

In summary, the regression analysis findings confirm the importance of learning-oriented partnerships between students, the teacher and parents for the attainment of educational outcomes. The importance of partnerships and concomitant values and behaviours for improving student learning is also a common finding of classroom and school effectiveness research (Halsall, 1998; Harris, 2001; Hopkins, 1995; Ofsted, 1995). However, regression analysis results failed to confirm positive relationships between caring behaviours of the teacher and students and attainment of educational outcomes.

\section{$\underline{\text { Implications for School Renewal }}$}


School renewal necessitates questioning prevailing practices and attitudes towards student learning and re-culturing to change belief and value systems throughout the school. The results of investigating associations between classroom culture attitudes and behaviours and educational outcomes have five implications for secondary school renewal. Firstly, classroom culture was found to have a significant influence on student educational outcomes ( $\mathrm{R}$ Square $\approx 0.40$ ). School renewal initiatives that develop appropriate attitudes and behaviours within classrooms are expected to result in higher levels of educational outcome attainment. Understanding the interaction between students, the teacher and parents, and examining how this interaction influences the development of positive beliefs and values towards student learning is crucial.

Secondly, assessing the effectiveness of classroom culture and school renewal requires decisions to be made about the particular types of educational outcomes to be assessed. The study differentiated between student values towards education and formal learning outcomes. Data on formal outcome attainment is typically applied in demonstrating accountability but may have limitations when used to inform improvement of classroom culture and school renewal. School renewal involves development of strong beliefs and values towards student learning and attitudinal scales should be applied to evaluate the outcomes of the renewal process.

Thirdly, successful school renewal can be perceived as a process of organisational learning concerning the learning of both students and teachers. Whilst it is obvious that the learning of students occurs mainly within the classroom, the classroom is also the most relevant setting for teacher learning and professional development. The teacher is part of the classroom learning environment and is a participant in the development of classroom culture. 
Teachers who understand the dynamics of the classroom culture, and reflect upon their own involvement in the culture, are more likely to be influenced by the culture and accordingly modify their instructional practices to suit the needs of students. This orientation can be contrasted with that of teachers who view their classroom role in terms of control and manipulation of the culture to suit their own dispositions. The differentiation between teacher control of the classroom culture and teacher participation in the culture are exemplified by the findings concerning teacher attitudes and behaviours towards students and instruction. Teacher's expectations of student's behaviour (teacher control) was found to be independent of collaborative and caring teacher behaviours.

Fourthly, curriculum implementation and school renewal are realised through classroom culture. The principles under-pinning school renewal concern development of positive student attitudes towards participation in society and engagement in learning. Formal recognition of the importance of developing these attitudes as explicated in local curriculum policy mandates is likely supportive of school renewal initiatives. However, realisation of curriculum policy intentions and renewal of schools requires more than congruency between curriculum policy and the theoretical conceptions of school renewal. Enactment of both curriculum policy and school renewal occurs within the classroom and the classroom culture is the vehicle for both curriculum implementation and school renewal. Investigating classroom culture provides valuable information on curriculum implementation and school renewal.

The fifth implication of the results of the study for school renewal concerns school leadership. In most local secondary schools, as students move between different subject area classes and receive instruction from different teachers, they experience many classroom cultures. Whilst mastery of specific instructional objectives might be achieved best by 
specialist teaching in suitably equipped classrooms, incongruence in expectations and values within the school-wide environment could restrict development of positive attitudes towards self, others and learning. Emphasising the importance of learning, applying a common pedagogy throughout the school and reinforcing socially accepted behaviours are attributes of school culture. An important aspect of the role of school leadership is coaching and mentoring other members of staff in the techniques of building and maintaining school culture. This includes modeling appropriate behaviours and also continually espousing the beliefs, values and attitudes that constitute the ideal school culture and are enshrined in the school's vision. In large secondary schools, the principal cannot be expected to have detailed knowledge of all aspects of the curriculum and of the instructional methods applied to achieve the formal learning outcomes associated with specialised areas of the curriculum. In such schools the orientation of the principal needs to be holistic with effort and energy being directed towards the core values and assumptions about learning that underpin the curriculum, the school vision and that constitute the school culture.

These five implications for secondary school renewal are consistent with the issues emerging in contemporary research into assessing the instructional effectiveness of schools (Fidler, 2001; Roberson, Sammons, Thomas \& Mortimore, 2001), the professional development of teachers (Bailey, 2000; Carter \& Halsall, 1998; Tisdell \& Taylor, 1999; Witcher, Sewall, Arnold \& Travers, 2001), curriculum reform (Gray, Hopkins, Reynolds, Wilcox, Farrell \& Jesson, 1999; Reynolds, 2001), and leadership of school renewal (Fink \& Resnick, 2001; Fullan, 2001; Meyer \& Macmillan, 2001). 


\section{CONCLUSION}

The study demonstrated the utility of correlational research methods and attitude scales for investigating classroom culture. Hypothesised relationships between classroom attitudes, behaviours and educational outcomes were tested and the results provided an insight into secondary school classroom culture. The empirically validated attributes of classroom culture investigated were discussed within the contexts of local curriculum driven educational reform and theoretical propositions about school renewal. The findings of the study have application in informing school improvement, the development of classroom learning environments conducive to improving the educational outcomes of students, and school-wide renewal of learning and teaching culture. 


\section{APPENDIX}

\section{Classroom Environment and Educational Outcomes Questionnaire}
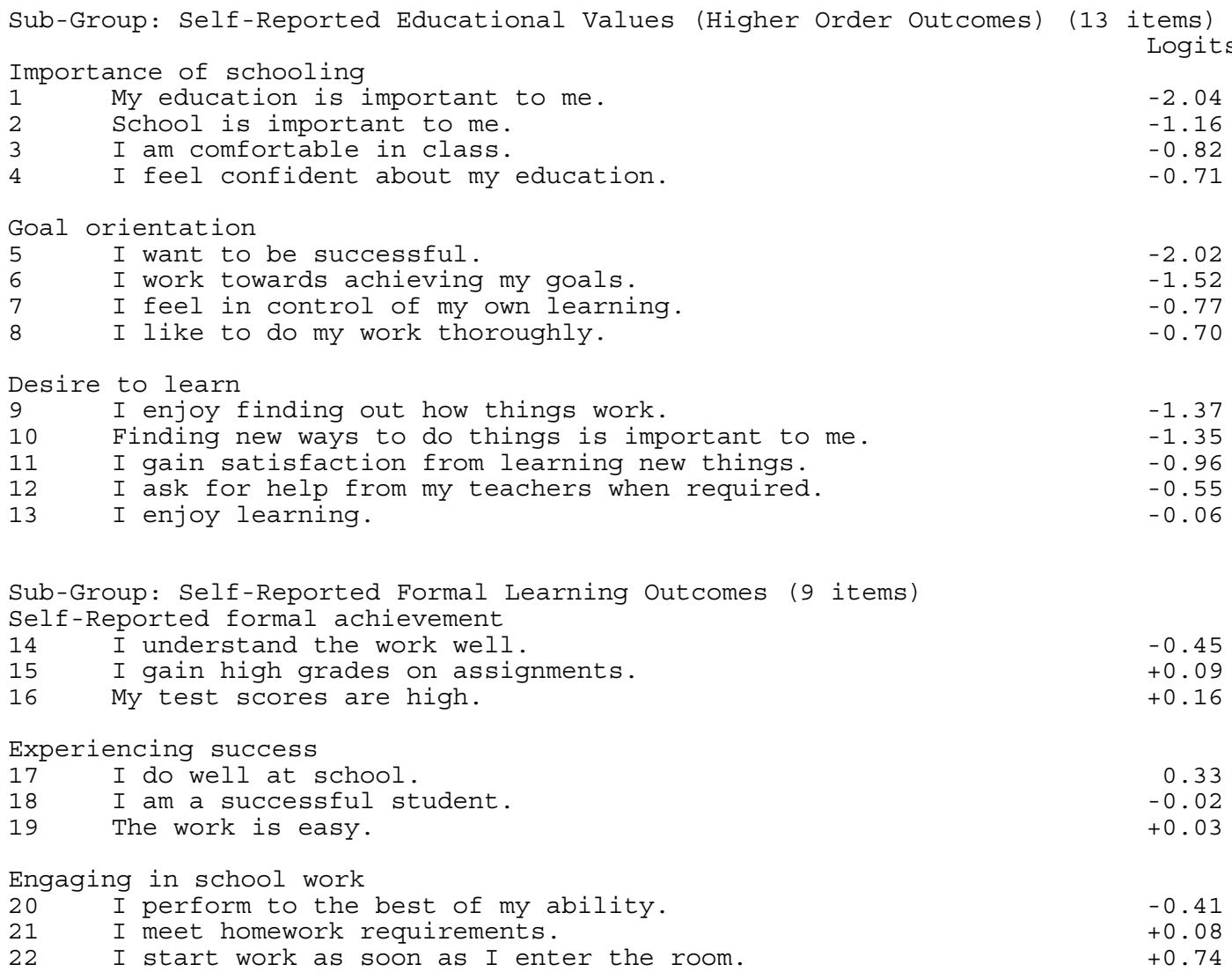

Sub-Group: Student Classroom Learning Attitudes and Behaviours (11 items)

Class emphasis on learning

23 Learning is really important in this class.

24 I find new ways to learn in this class.

25 We spend time thinking about how our studies are going. +0.33

26 We don't waste time in this class.

Class learning with peers

$\begin{array}{ll}27 & \text { Students learn from each other. } \\ 28 & \text { I take notice of what my classmates have to say about our learning }-0.32\end{array}$

29 Students do not stop others from working. +0.75

Class emphasis on performing well

30 We expect our test scores and/or grades to be high.

31 Our work is marked quickly. +0.33

32 We are rewarded for doing well. +0.44

33 The top students in this class are respected by others. $\quad+0.84$

Sub-Group: Student Classroom Support Attitudes and Behaviour (11 items)

Helping each other

34 Students support each other. +0.11

35 Students are willing to help each other when problems arise. +0.16

36 Students always encourage each other to express our opinions. +0.26

37 Students share problems with each other. $\quad+0.28$

Getting along together

38 Students look forward to being together. 0.10

39 Students make an effort to get on well with each other. $\quad+0.02$

40 Our classroom is a happy place. +0.27

41 My views are supported by my classmates. $\quad+0.28$ 
Caring about each other

Students are tolerant of one another. +0.29

Students care for each other. +0.28

44 Students are not nasty towards each other. +0.66

$\begin{array}{lll}\text { Sub-Group: Student Classroom Discussion Behaviour (5 items) } & \\ \text { Classroom discussion about learning } & +0.01 \\ 45 & \text { There is a lot of talk about important matters. } & +0.14 \\ 46 & \text { We talk about our test scores and grades. } & +0.32 \\ 47 & \text { We spend time discussing what should happen in this class. } & +0.38 \\ 48 & \text { We have discussions about what we should be learning. } & +0.48\end{array}$

Sub-Group: Student Classroom Planning Behaviour (3 items)

Sharing classroom planning with the teacher

50 We are involved in deciding how our progress will be assessed. +0.82

51 We are given assessment tasks or tests when we are ready. +0.89

52 We set the deadlines with the teacher for completing work. +1.09

Sub-Group: Student Views of Teachers' Behaviour to Decision-Making (2 items)

53 The teacher does not dominate us. +0.21

54 The teacher asks our advice. +0.60

Sub-Group: Student Views of Teachers' Behaviour to Caring (4 items)

55 The teacher takes the side of students who are treated unfairly by others.

$+0.54$

56 The teacher helps students who get into trouble around the school. +0.99

57 The teacher helps students with family problems. +1.36

58 At times, the teacher seems more like a mum or dad than a teacher. +1.46

Sub-Group: Student Views of Teachers' Expectations for Students (3 items)

59 The teacher expects all students to be fully committed to their work.

60 The teacher sets high standards.

61 The teacher has high expectations of us. 0.28

Sub-Group: Student Views of Parents' Attitudes and Behaviour (5 items)

62 My parent (s) take an interest in my progress. -0.14

63 My parent (s) are not critical of the teacher. +0.18

64 My parent (s) are informed when I produce excellent work. +0.72

65 My parent (s) are given frequent information on my progress. +0.86

66 My parent $(\mathrm{s})$ communicate with the teacher. 0.96 


\section{REFERENCES}

Andrich, D., Sheridan, B., Lyne, A. \& Luo, G. (2000). RUMM: A windows-based item analysis program employing Rasch unidimensional measurement models. Perth: Murdoch University.

Bailey, B. (2000). The impact of mandated change on teachers. Bascia, N. \& Hargreaves, A. (eds).The sharp edge of educational change: teaching, leading and the realities of reform. London: Routledge Falmer.

Bascia, N. \& Hargreaves, A. (2000). Teaching and leading on the sharp edge of change. Bascia, N. \& Hargreaves, A (eds).The sharp edge of educational change: teaching, leading and the realities of reform. London: Routledge Falmer.

Battistitch, V., Solomon D., Watson, M. \& Schaps, E. (1997). Caring school communities. Educational Psychologist, 32(3), 137-151.

Blumenfield, , P. C., Marx, R. W., Patrick, H., Krajcik, J., \& Soloway, E. (1997). Teaching for understanding. In B. J. Biddle \& T. L. Good \& I. F. Goodson (Eds.), International handbook of teachers and teaching Dordrecht; Boston: Kluwer Academic Publishers.

Boland, T., Cavanagh, R.F. \& Dellar, G.B. (2001). Evaluation of school restructuring intended to create a middle schooling culture Paper presented at the 2001 Annual Conference of the Australian Association for Research in Education: Fremantle.

Carter, K. \& Halsall, R. (1998). Teacher research for school improvement. Halsall (ed). Teacher research and school improvement: opening doors from the inside. Buckingham: Open University press.

Cavanagh, R.F. \& Dellar, G.B. (2001). School improvement: organisational development or community building?. Paper presented at the 2001 Annual Conference of the Australian Association for Research in Education, Fremantle, December 3 -6, 2001.

Coleman, P. (1998). Parent, student and teacher collaboration: the power of three. Corwin Press Inc: California.

Crowther, F., Kaagan, S.S., Ferguson, M. \& Hann, L. (2002). Developing teacher leaders. Thousand Oaks, California: Corwin Press, Inc.

Curriculum Council. (1997).Curriculum Framework. Perth: Curriculum Council of Western Australia.

Dalin, P., Rolff, H. and Kleekamp, B. (1993). Changing the school culture. London: Cassell.

Fidler, B. (2001). A structural critique of school effectiveness and improvement. Harris, A. \& Bennett, N. (eds). School effectiveness and improvement: alternative perspectives. London: Continuum.

Fink, E. \& Resnick, L.B. (2001). Developing principals as instructional leaders. Phi Delta Kappan, 82(8), 598- 618. 
Fullan, M. (2001). Leading in a culture of change. San Francisco: Jossey Bass.

Fullan, M.G. (1993). Change forces probing the depths of educational reform. London: The Falmer Press.

Fullan, M.G. \& Hargreaves, A. (1992). Whats worth fighting for in your school? Buckingham: Open University Press.

Glickman, C.D. (1992). The essence of school renewal: the prose has begun. Educational Leadership, 50 (1).

Good, T. L. (1996). Teaching effects and teacher evaluation. In J. Sikula \& T. J. Buttery \& E. Guyton (eds.), Handbook of research on teacher education (2nd ed). New York, NY: Simon and Schuster Macmillan.

Good, T. L., \& Brophy, J. E. (2000). Looking in classrooms (8th ed.). New York, NY: Addison Wesley

Good, T. L., Biddle, B. J., \& Goodson, I. F. (1997). The study of teaching: Modern and emerging conceptions. Biddle, B.J., Good, T.L. Goodson, I.F. (eds.), International handbook of teachers and teaching Dordrecht; Boston: Kluwer Academic Publishers.

Gray, J., Hopkins, D., Reynolds, D., Wilcox, B., Farrell, S. \& Jesson, D. (1999). Improving schools performance and potential. Buckingham: Open University press.

Halsall, R. (1998). School improvement: an overview of key findings and messages. Halsall (ed). Teacher research and school improvement: opening doors from the inside. Buckingham: Open University press.

Hargreaves, A. (1994). Changing teachers, changing times: teachers' work and culture in the postmodern age. London: Cassell.

Hargreaves, A. (1995) Renewal in the age of paradox. Educational Leadership, 52(7). Harris, A. (1999). Teaching and learning in effective schools. Aldershot: Ashgate Publishing Company.

Harris, A. (2001). Contemporary perspectives on school effectiveness and school improvement. Harris, A. \& Bennett, N. (eds). School effectiveness and improvement: alternative perspectives. London: Continuum.

Hopkins, D. (1995). Successful school improvement: what works and why. Inaugural Conference of the North West Consortium for the Study of Effectiveness in Urban Schools, Wigan, July.

Johnson, D.W., Johnson, R.T. \& Stanne, M.B. ( 2000). Cooperative learning methods: a meta-analysis. Minneapolis: Cooperative Learning Center. [WWW document]. URL http://www.clcrc.com/pages/cl-methods.html

Lingard, B. (2001). Some lessons for educational researchers: repositioning research in education and education in research. The Australian Educational Researcher, 28(3), 1-46. 
MacBeath, J. \& Mortimore, P. (2001). Improving school effectiveness. Buckingham: Open University Press.

MCEETYA. (2000). The Adelaide Declaration on National Goals for Schooling in the Twenty-first Century. Carlton South, Victoria: MCEETYA.

Meyer, M.J. \& Macmillan, R.B. (2001). The principal's role in transition: instructional leadership ain't what it used to be. International Electronic Journal for Leadership in Learning, 5(13).

Newmann, F.M. \& Associates. (1996). Authentic achievement: restructuring schools for intellectual quality. San Francisco: Jossey-Bass.

Ofsted. (1995). Guidance on the inspection of secondary schools. London: HMSO.

Queensland Department of Education. (2001). The Queensland school reform longitudinal study: teachers' summary. Brisbane: The State of Queensland (Department of Education).

Pena, R.A. \& Amrein, A.L. (1999). Classroom management and caring: a primer for administrators and teachers. International Electronic Journal for Leadership in Learning, $3(24)$.

Reynolds, d. (2001). Harris, A. \& Bennett, N. (eds). School effectiveness and improvement: alternative perspectives. London: Continuum.

Robertson, P. \& Toal, D. (2001). Extending the quality framework: lessons from case study schools. MacBeath, J. \& Mortimore, P. (eds). Improving school effectiveness. Buckingham: Open University press.

Robertson, P., Sammons, P., Thomas, S. \& Mortimore, P. (2001). MacBeath, J. \& Mortimore, P. (eds). Improving school effectiveness. Buckingham: Open University press.

Sirotnik, .K.A. (1999). Making sense of educational transformation. Phi Delta Kappan, 80(8), 606-610.

Soder, R. (1999). When words find their meaning: transformation versus reform. Phi Delta Kappan, 80(8), 568-570.

Stoll, L., MacBeath, J. \& Mortimore, P. (2001). Beyond 2000: where next for effectiveness and improvement. MacBeath, J. \& Mortimore, P. (eds). Improving school effectiveness. Buckingham: Open University press.

Tisdell, E. \& Taylor, E.W. (1999). Adult education philosophy informs practice. Adult Learning, 11(2), 6-15.

Waugh, R.F. \& Cavanagh, R.F. (2002a). Linking classroom environment with educational outcomes using a Rasch measurement model. Paper presented at the Australian Association for Research in Education Conference, Brisbane. 
Waugh, R.F. \& Cavanagh, R.F. (2002b). Measuring parent receptivity towards the classroom environment using a Rasch measurement model. Accepted for publication in the Journal of Learning Environments Research.

Witcher, A.E., Sewall, A.M., Arnold, L.D. \& Travers, P.D. (2001). Teaching, leading, learning: it's all about philosophy. The Clearing House, 74(5) 277-284.

Wright, B.D. \& Masters, G.N. (1982). Rating scale analysis: Rasch measurement. Chicago. IL: MESA. 
FIGURES AND TABLES

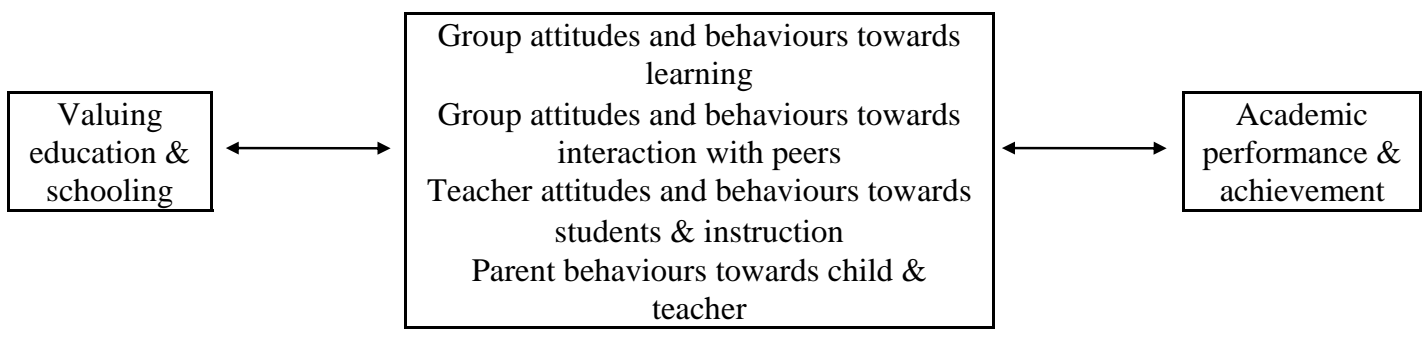

Figure 1: Model of classroom culture

Table 1

Dependent and independent variables, number of items and sample items

\begin{tabular}{lll}
\hline Scale & $\begin{array}{l}\text { Number } \\
\text { of items }\end{array}$ & \\
\hline
\end{tabular}

Dependent variables

1. Student educational values

13 My education is important for me

I work towards achieving my goals

I enjoy learning

2. Formal learning outcomes

$9 \quad$ I gain high grades on assignments

I am a successful student

I perform to the best of my ability

Independent variables

Group attitudes and behaviours towards

learning

1. Class emphasis on learning

2. Class learning with peers

3. Class emphasis on performing well

Group attitudes and behaviours towards

interaction with peers

4. Helping each other

5. Getting along together

6. Caring about each other

7. Student classroom discussion behaviour

Teacher attitudes and behaviours towards students \& instruction

8. Student classroom planning behaviour

9. Teacher's behaviour to decision-making

10. Teacher's behaviour to caring

11. Teacher's expectations for students

Parent attitudes \& behaviours towards

child \& teacher

12. Parent attitudes and behaviours
Learning is really important in this class

Students learn from one another

The top students in this class are respected by others

Students share problems with each other

Students make an effort to get on well with each other Students care for each other

We have discussions about what we should be learning

We are involved in deciding how our progress will be assessed

The teacher asks our advice

The teacher helps students with family problems

3 The teacher sets high standards

$5 \quad$ My parents take an interest in my progress 
Table 2

Population and valid surveys

\begin{tabular}{lll}
\hline Year & Population & Valid surveys \\
\hline Eight & 246 & 183 \\
Nine & 243 & $311^{*}$ \\
Ten & 248 & $309^{*}$ \\
Eleven & 212 & 185 \\
Twelve & 179 & Not surveyed \\
Total & 1128 & 988 \\
\hline
\end{tabular}

* Some students surveyed twice in different classes

Table 3

Sample stratification by year and subject

\begin{tabular}{lcl}
\hline Year & Number of class groups & Subject areas (number of valid surveys) \\
\hline Eight & 8 & English (109) and Society \& \\
& & Environment (74) \\
Nine & 16 & Mathematics (68), Science (85) and \\
& 17 & Electives (158) \\
Ten & 12 & Mathematic (92), Science (73) and \\
& & Electives (144) \\
Eleven & 12 & All subject areas (185) \\
\hline
\end{tabular}

Table 4

Data reliability $(n=988)$

\begin{tabular}{ll}
\hline Scale & Cronbach's Alpha \\
\hline Student educational values (13 items) & 0.89 \\
Formal learning outcomes (9 items) & 0.89 \\
Group attitudes and behaviours towards learning (11 items) & 0.81 \\
1. Class emphasis on learning (4 items) & 0.63 \\
2. Class learning with peers (3 items) & 0.49 \\
3. Class emphasis on performing well (4 items) & 0.66 \\
Group attitudes and behaviours towards interaction with peers (16 items) & 0.89 \\
4. Helping each other (4 items) & 0.68 \\
5. Getting along together (4 items) & 0.64 \\
6. Caring about each other (3 items) & 0.75 \\
7. Student classroom discussion behaviour (5 items) & 0.76 \\
Teacher attitudes and behaviours towards students \& instruction (12 items) & 0.86 \\
8. Student classroom planning behaviour (3 items) & 0.72 \\
9. Teacher's behaviour to decision-making (2 items) & 0.61 \\
10. Teacher's behaviour to caring (4 items) & 0.80 \\
11. Teacher's expectations for students (3 items) & 0.74 \\
Parent attitudes \& behaviours towards child \& teacher (5 items) & 0.75 \\
12. Parent attitudes and behaviours (5 items) & 0.75 \\
Instrument (66 items) & 0.95 \\
\hline
\end{tabular}


Table 5

Correlations between independent variables $(n=988)$

\begin{tabular}{|c|c|c|c|c|c|c|c|c|c|c|c|}
\hline Independent variables & 1 & 2 & 3 & 4 & 5 & 6 & 7 & 8 & 9 & 10 & 11 \\
\hline \multicolumn{12}{|l|}{$\begin{array}{l}\text { Group attitudes and behaviours towards } \\
\text { learning }\end{array}$} \\
\hline 1. Class emphasis on learning & 1.00 & & & & & & & & & & \\
\hline 2. Class learning with peers & .56 & 1.00 & & & & & & & & & \\
\hline 3. Class emphasis on performing well & .60 & .54 & 1.00 & & & & & & & & \\
\hline \multicolumn{12}{|l|}{$\begin{array}{l}\text { Group attitudes and behaviours towards } \\
\text { interaction with peers }\end{array}$} \\
\hline 4. Helping each other & .43 & .54 & .46 & 1.00 & & & & & & & \\
\hline 5. Getting along together & .44 & .52 & .45 & .74 & 1.00 & & & & & & \\
\hline 6. Caring about each other & .41 & .48 & .45 & .62 & .73 & 1.00 & & & & & \\
\hline 7. Student classroom discussion behaviour & .51 & .40 & .48 & .41 & .44 & .39 & 1.00 & & & & \\
\hline \multicolumn{12}{|l|}{$\begin{array}{l}\text { Teacher attitudes and behaviours towards } \\
\text { students \& instruction }\end{array}$} \\
\hline 8. Student classroom planning behaviour & .28 & .24 & .34 & .27 & .28 & .24 & .47 & 1.00 & & & \\
\hline 9. Teacher's behaviour to decision-making & .30 & .27 & .36 & .31 & .34 & .24 & .42 & .41 & 1.00 & & \\
\hline 10. Teacher's behaviour to caring & .27 & .16 & .40 & .24 & .25 & .20 & .43 & .43 & .48 & 1.00 & \\
\hline $\begin{array}{l}\text { 11. Teacher's expectations for students } \\
\text { Parent attitudes \& behaviours towards } \\
\text { child \& teacher }\end{array}$ & .33 & .37 & .31 & .26 & .28 & .20 & .24 & .09 & .11 & .09 & 1.00 \\
\hline 12. Parent attitudes and behaviours & .38 & .28 & .37 & .28 & .31 & .23 & .44 & .37 & .39 & .43 & .28 \\
\hline
\end{tabular}

Note: $\mathrm{p}<0.001$ for all the above correlations.

Table 6

Correlations of independent variables with dependent variables $(n=988)$

\begin{tabular}{lll} 
& \multicolumn{2}{c}{ Dependent variables } \\
\cline { 2 - 3 } Independent variables & $\begin{array}{l}\text { Student educational } \\
\text { values }\end{array}$ & $\begin{array}{l}\text { Formal learning } \\
\text { outcomes }\end{array}$ \\
\hline Group attitudes and behaviours towards learning & & \\
1. Class emphasis on learning & 0.58 & 0.48 \\
2. Class learning with peers & 0.46 & 0.41 \\
3. Class emphasis on performing well & 0.50 & 0.50 \\
Group attitudes and behaviours towards & & \\
interaction with peers & & \\
4. Helping each other & 0.31 & 0.33 \\
5. Getting along together & 0.37 & 0.39 \\
6. Caring about each other & 0.33 & 0.28 \\
7. Student classroom discussion behaviour & 0.39 & 0.40 \\
Teacher attitudes and behaviours towards & & \\
students \& instruction & & 0.30 \\
8. Student classroom planning behaviour & 0.17 & 0.28 \\
9. Teacher's behaviour to decision-making & 0.22 & 0.26 \\
10. Teacher's behaviour to caring & 0.14 & 0.39 \\
11. Teacher's expectations for students & 0.37 & \\
Parent attitudes \& behaviours towards child \& & & 0.41 \\
teacher & & \\
12. Parent attitudes and behaviours & 0.32 & \\
\hline
\end{tabular}

Note: $\mathrm{p}<0.001$ for all the above correlations. 
Table 7

Dependent variable student educational values $(n=988)$

Multiple R $=0.64$

$\mathrm{R}$ Square $=0.41$

Analysis of Variance: $F=57.4$ Sig $F=0.000$

\begin{tabular}{|c|c|c|c|c|c|}
\hline Independent variables & $\mathrm{B}$ & Std error B & $\beta$ & $\mathrm{t}$ & Sig t \\
\hline \multicolumn{6}{|c|}{ Group attitudes and behaviours towards learning } \\
\hline 1. Class emphasis on learning & 0.89 & 0.09 & 0.33 & 9.64 & $0.000 *$ \\
\hline 2. Class learning with peers & 0.31 & 0.12 & 0.09 & 2.68 & 0.008 \\
\hline 3. Class emphasis on performing well & 0.45 & 0.09 & 0.18 & 5.14 & $0.000 *$ \\
\hline \multicolumn{6}{|l|}{$\begin{array}{l}\text { Group attitudes and behaviours towards } \\
\text { interaction with peers }\end{array}$} \\
\hline 4. Helping each other & -0.21 & 0.09 & -0.09 & -2.37 & 0.018 \\
\hline 5. Getting along together & 0.25 & 0.11 & 0.10 & 2.20 & 0.028 \\
\hline 6. Caring about each other & 0.00 & 0.11 & 0.00 & 0.03 & 0.978 \\
\hline 7. Student classroom discussion behaviour & 0.17 & 0.07 & 0.08 & 2.51 & 0.012 \\
\hline \multicolumn{6}{|l|}{$\begin{array}{l}\text { Teacher attitudes and behaviours towards } \\
\text { students \& instruction }\end{array}$} \\
\hline 8. Student classroom planning behaviour & -0.13 & 0.08 & -0.05 & -1.63 & 0.105 \\
\hline 9. Teacher's behaviour to decision-making & 0.08 & 0.11 & 0.02 & 0.67 & 0.502 \\
\hline 10. Teacher’s behaviour to caring & -0.22 & 0.06 & -0.11 & -3.53 & $0.000^{*}$ \\
\hline 11. Teacher’s expectations for students & 0.40 & 0.09 & 0.13 & 4.62 & $0.000^{*}$ \\
\hline \multicolumn{6}{|l|}{$\begin{array}{l}\text { Parent attitudes \& behaviours towards child \& } \\
\text { teacher }\end{array}$} \\
\hline 12. Parent attitudes and behaviours & 0.15 & 0.05 & 0.08 & 2.78 & 0.006 \\
\hline Constant & 18.4 & 1.04 & & 17.7 & 0.000 \\
\hline
\end{tabular}

* indicates significant Beta weights.

Table 8

Dependent variable formal learning outcomes $(n=988)$

Multiple $\mathrm{R}=0.62$

$\mathrm{R}$ Square $=0.39$

Analysis of Variance: $F=50.9$ Sig $F=0.000$

\begin{tabular}{lccccc}
\hline Independent variables & B & Std error B & $\beta$ & t & Sig t \\
\hline Group attitudes and behaviours towards learning & & & & & \\
1. Class emphasis on learning & 0.36 & 0.09 & 0.15 & 4.21 & $0.000^{*}$ \\
2. Class learning with peers & 0.15 & 0.11 & 0.05 & 1.34 & 0.181 \\
3. Class emphasis on performing well & 0.49 & 0.08 & 0.22 & 6.12 & $0.000^{*}$ \\
Group attitudes and behaviours towards & & & & & \\
interaction with peers & & & & & \\
4. Helping each other & -0.06 & 0.08 & -0.03 & -0.74 & 0.463 \\
5. Getting along together & 0.36 & 0.10 & 0.15 & 3.44 & $0.001^{*}$ \\
6. Caring about each other & -0.28 & 0.10 & -0.11 & -2.77 & $0.006^{*}$ \\
7. Student classroom discussion behaviour & 0.08 & 0.06 & 0.04 & 1.27 & 0.206 \\
Teacher attitudes and behaviours towards & & & & & \\
students \& instruction & & & & & \\
8. Student classroom planning behaviour & 0.18 & 0.07 & 0.07 & 2.44 & 0.015 \\
9. Teacher's behaviour to decision-making & 0.05 & 0.11 & 0.01 & 0.44 & 0.664 \\
10. Teacher's behaviour to caring & -0.05 & 0.06 & -0.03 & -0.87 & 0.387 \\
11. Teacher's expectations for students & 0.51 & 0.08 & 0.18 & 6.32 & $0.000^{*}$ \\
Parent attitudes \& behaviours towards child \& & & & & & \\
teacher & & & & & \\
12. Parent attitudes and behaviours & 0.25 & 0.05 & 0.15 & 4.98 & $0.000^{*}$ \\
\hline Constant & 4.01 & 0.97 & & 4.15 & 0.000 \\
\hline * indicates significant Beta weights & & & &
\end{tabular}

* indicates significant Beta weights. 